\title{
What Should We Do With Traditional Logic?
}

\section{Jesse P. Bohl}

\begin{abstract}
There is a clash between some people's positive logical intuitions about traditional or Aristotelian logic and the assessment of that logic made by modern logic. In response to the clash, four sorts of reasons that might be given for preferring one logic to the other are considered, but it is argued that none of them provides a decisive reason in favor of one rather than the other. A reformist and a radical response to the apparent inability to give reasons to prefer one logic to the other are considered and reasons given for preferring the radical response.
\end{abstract}

Résumé: Il y a un conflit entre les intuitions typiques sur la logique traditionnelle ou aristotélicienne et l'évaluation de celle-ci par la logique moderne. On examine quatre sortes de raisons avancées pour préférer une logique plutôt qu'une autre, mais on soutient qu'aucune de ces raisons n'est décisive. À cette impasse on avance et appuie une réplique réformiste et radicale.

Keywords: modern logic, traditional logic, semantics, formal systems, ontology, necessity, natural language and logic, uses of formal logic

From the point of view of modern logic, conceived as first-order predicate logic, traditional logic got most of the relations in the traditional square of opposition wrong and judged valid nine valid forms of the categorical syllogism which are "in fact" invalid. By traditional logic I mean the fourteen moods in the first three figures explicitly laid out by Aristotle (1941, 25b27-29a17), the ten additional moods in all four figures later added to Aristotle's list, the immediate arguments, and relations in the square of opposition recognized by Aristotle (1941, 17a25-18a12) plus subalternation.' The alleged mistakes that ground these supposed misjudgments were to suppose that universal propositions have existential import and that particular propositions have no existential import. These "mistakes" account for each case in which allegedly invalid arguments were taken for valid ones. For example, according to traditional logic, the contraries "All phlogiston is pure" and "No phlogiston is pure" cannot both be true; modern logic holds that both are true because there is no such thing as phlogiston. On the other hand, the sub-contraries "Some kryptonite is lethal" and "Some kryptonite is not lethal" cannot both be false according to traditional logic, but modern logic takes both as false on the 
grounds that there is no such thing as kryptonite. Again, traditional logic marks the argument from "All Lilliputians are small persons" and "All small persons are clever" to "Some Lilliputians are clever" as valid, while modern logic marks it as invalid on the grounds that there are no Lilliputians. Thus, modern logic can use the two alleged mistakes to explain why the arguments and logical relations traditional logic took to be correct are apparently not correct.

However, as anyone who perhaps foolishly has taught the same students both traditional logic and the modern criticisms of that logic knows, there is a decided tension between the modern logic's treatment of traditional logic and the logical intuitions of students. ${ }^{2}$ On one hand, the students tend to find the logically rich traditional Aristotelian square and the twenty four traditionally valid forms of syllogism quite persuasively in accord with their own logical intuitions. On the other, when the students discover that modern logic treats both "All unicorns are white" and "All unicorns are magenta with ocher piebalding" as true and both "Some gods are humanly formed" and "Some are not humanly formed" as false, modern logic strikes them as profoundly counterintuitive and thus unpersuasive. Moreover, students understandably find it puzzling that the alleged mistakes in traditional logic went unnoticed for so long. Untutored students are not the only ones who find modern logic's treatment of categoricals counter intuitive: J.L Austin (1970, p. 223 ) also found it "curious" to interpret universal categoricals as conditionals.

There are several ways in which one might respond to the tension between students' (and others') intuitions about traditional logic and modern logic's claims about it. The brusquest is simply to dismiss these intuitions along with the moral, aesthetic, and religious variety as quite irrelevant to clear thinking. A somewhat gentler response is that such intuitions, although persuasive to those having them, ought to be overcome by proper schooling in logic. The recent work of Sommers (1982), Englebretsen $(1981,1987)$ and others might be taken to suggest another possibility. Their New Syllogistic accepts modern logic's criticism and builds existential import into universal categoricals. This move does succeed in marking as valid those syllogistic arguments traditional logic marked as valid, but, because it can not reproduce the traditional square, it is a third alternative to modern and traditional logic rather than a formal reconstruction of traditional logic. Since the contrast between modern and traditional logic is starker than that between either and the New Syllogistic, I will consider only traditional and modern logic below. The final response to the tension between modern logic and some people's logical intuitions is to offer reasons for preferring modern to traditional logic. In the first section below, I will examine four sorts of reasons that might be offered for preferring modern to traditional logic and explain why I find these reasons undecisive. Having reached an impasse on the question of which of the two logics is better, I will in the second section consider two responses to the clash between traditional and modern logic, give reasons for rejecting one, and develop some of the implications of the other. 
The first reason one might prefer modern to traditional logic is one we might call purely formal. The idea is that Aristotelian logic is a weaker formal system than modern logic because modern logic validates more arguments than does traditional logic. Moreover, it is claimed that modern logic can subsume traditional logic, but not vice versa. But modern logic can only subsume traditional logic by maintaining that some of the arguments that traditional logic conceived as a formal system takes as valid are invalid. ${ }^{3}$ If this is what is meant by subsumption, then we are begging the question against traditional logic. We also need to consider what is involved in validating an argument by appeal to a formal system. There are two steps involved in the process of validation: symbolization of the argument; and use of some method such as proof, semantic tableau, etc., to determine whether the argument is valid. However, if the symbolization is shown invalid, we cannot say the original argument is invalid, because there might be another symbolization that shows the argument valid. Thus, to show the allegedly problematic arguments of traditional logic are invalid when they are rendered into modern logical symbolism does not finally settle the question of their validity. Moreover, of course, those same arguments symbolized in the traditional way are valid, so it seems we ought to accept them as valid, since it takes only one symbolization showing an argument valid for the argument to be validated. Now, there is no doubt that modern logic provides means of validating more arguments than traditional logic does because there are obviously valid arguments that cannot be shown to be valid in traditional logic. That is, of course, why various logical rules supplemented traditional logic. However, we do not just want a system that validates a lot of arguments; if we did, we would prefer an inconsistent system because it validates every argument. What we want is a system that validates the correct arguments. But then the formal system by itself cannot decide the question of whether an argument is valid, since its use as a means of validation is dependent on our already having a pretty good idea of which the arguments ought to be validated by a formal system.

The second reason one might prefer modern to traditional logic preserves the connection between formal systems and natural language that has grounded the usefulness of formal systems for twentieth-century analytic philosophy. We might, following Davidson, call this second reason a semantic one. Davidson (1965, $1967,1969,1970$ ) at one time took a semantic theory for a natural language to be an empirically grounded set of recursive rules for pairing natural language sentences with sentences in a perspicuous formal metalanguage. A metalanguage is perspicuous to the degree that it makes plain the truth conditions of sentences in the object language and the inferential relations between those sentences. The empirical grounding for such a theory is the degree to which it maximizes both the pairing of held-true sentences in the object language with true sentences in the metalanguage and the pairing of arguments held valid in the object language with valid arguments in the metalanguage. 
Using Davidson's conception of semantic theory, we can ask whether traditional or modern logic provides us with a more perspicuous metalanguage. Modern logic gives us some matching of held true sentences with false sentences and vice versa since it sees all rather than only some universal sentences about allegedly nonexistent entities as true and all rather than only some particular sentences about these entities as false. In contrast, traditional logic preserves the intuitions that "All centaurs are half human and half horse", "Some gods are female" and "Some gods are not female" are true and that "No centaurs are half human and half horse" is false. Traditional logic might also preserve the intuitions that it is true that Hamlet is a prince of Denmark and false that Hamlet is a serf in France. It is commonplace to note that Aristotle (1941, 13b11-36) himself acknowledges that if Socrates does not exist, then "Socrates is sick" is false and "Socrates is not sick" is true. Modern logicians are quick to agree about the former although they disagree about the latter, because his view about the former suggests a glimmer of the view held by modern logicians. However, Aristotle (1941, 21a20-35) also claims that it is correct to say that Homer is a poet even though Homer no longer exists. Obviously, one might simply respond that Aristotle ought not to have claimed that "Homer is a poet" is true, since that claim is inconsistent with his more often made claim that affirmative particular claims about the non-existent are false and negative particular claims about them are true. Another way to make sense of Aristotle's different responses to sentences seen by modern logic to have the same logical form and thus the same reason for being false is to claim that the Socrates propositions ascribe accidential properties while the Homer sentence ascribes an essential property. One might then go on to say that particular propositions ascribing essential properties may be true or false regardless of the supposed actual existence, now or ever, of their subjects, while all affirmative particular propositions ascribing accidental properties to the non-existent are false, and all negative particular propositions ascribing accidental properties to the non-existent are true. No doubt most modern logicians and philosophers of language will dismiss such a suggestion out of hand, since it muddies the supposedly sharp distinction between clean logical form and messy semantic content.

In any case, insofar as traditional logic allows some universal statements about the allegedly non-existent to be false, some particular statements about allegedly non-existent individuals to be true and some false, there is a better true-true pairing in traditional than in modern logic. ${ }^{4}$ Traditional logic gives us a better true-true pairing but does so at the cost of seeing all atomic sentences, including those seen as relational by modern logic, as having subject-predicate logical structure. Moreover, both logics are incomplete with respect to the arguments warranted in the object language. An interesting point about the argument pairings is that both logics fail to warrant some of the arguments warranted by the other. Aristotle as well as his Stoic and Medieval successors recognized that his logic had to be supplemented with the laws of non-contradiction and excluded middle, modus ponens, modus tollens, etc. On the other hand, first-order predicate logic is unable to 
warrant all the categorical arguments warranted by traditional logic. Davidson (1970, p. 144) acknowledged that first-order predicate logic, his metalanguage of choice, must accept what he called "supplemental principles" to account for such arguments as that from "John is human" to "John is not a frog." It seems then that the semantic reason doesn't provide a convincing reason to prefer modern to traditional logic.

A third reason we might prefer modern to traditional logic is one I call ontologico-semantic simplicity. The point is to consider what beings must be posited to give a semantic account of a natural language. As we all know, Aristotle (1941, 2a10-15) makes a fundamental ontological distinction between individuals and qualities. The distinction is drawn in a suggestively semantic way: universals or properties are those beings that are predicable while individuals or primary substances are those which are not predicable. For Aristotle (1941, 2a33-2b6) neither of these two sorts of beings is in any sense reducible to the other. Moreover, he claims (1941, 1026a26-35) the two are ontologically codependent insofar as qualities cease to exist when there is no individual which the quality is truly predicable of and individuals are always individuals of a kind. Attempts at reduction, for example the repeated attempts in the empiricist/positivist tradition to construct individuals from their properties seen as ideas or sense-data, arrive on the scene later.

A counter-move typical of twentieth century Anglo-American philosophy is attempting to reduce qualities to individuals. Generally, properties and relations are understood as sets, i.e., as collections entirely equivalent to the collected members. The identity conditions of sets are particularly revealing: set $A$ and set $B$ are the same set if and only if A and B have exactly the same members. Thus, the members of the sets, individuals, become the fundamental entities, while qualities, construed as sets, are ontologically parasitic upon individuals. In order to avoid the oddity of apparently different qualities true of just the same individuals, or of none, being identical via set reduction, some make the move to reducing qualities to sets of possible individuals. This move has the same logic as set reduction, i.e., eliminating qualities in favor of individuals. Despite their alleged ontological superfluity, properties, or more precisely, property terms, are generally seen as useful in giving us a way of specifying sets, since there are very few sets which we can specify through naming each of their members. Thus modern logic seems ontico-semantically simpler than traditional logic, since the former has one basic ontological being while traditional logic has two.

The semantic difference between what traditional and modern logic count as intra-sentential and inter-sentential relations is conjoint with the ontological difference. For Aristotle, there are four irreducible intra-sentential relations: complete inclusion (A-form), complete exclusion (E-form), at least partial inclusion (I-form) and at least partial exclusion (O-form). ${ }^{5}$ Moreover, Aristotle takes the intra-sentential relations as the basis for the inter-sentential relations of his logic. In contrast, modern logic understands there to be one intra-sentential relation, that of individual 
to individual. The apparent intra-sentential relation of individual subject and universal predicate is construed as reducible to a relation of individual to individual, treating predicates as sets. Further, the apparently universal-universal intra-sentential relation in such sentences as "All persons are mortal" is read as a mere notational transform of originally inter-sentential relations. The anomaly of connectives defined inter-sententially being used intra-sententially is usually ignored or slid over with a mumble. The difference between the logical priority of intra- and intersentential relations in the two logics is interestingly displayed by the opposite approaches we use in teaching traditional and modern logic. In traditional logic we first teach the four intra-sentential forms, and then move to the inter-sentential relations, i.e., the square and the syllogism. When we teach modern logic we come at it the other way around: we start with the inter-sentential relations, i.e., sentential or propositional logic, then move on to the intra-sentential relation in predicate logic. In any case, traditional logic appears semantically more complex, because it has four intra-sentential relations while modern logic has only one. Traditional logic thus appears more complex both semantically and ontologically.

Laid out in this way it looks very much like ontico-semantic simplicity can neatly cut away traditional logic in favor of modern logic since the former is considerably more complex both ontologically and semantically. But it is well to remember here the "beyond necessity" handle of Ockham's razor. If our logic is supposed to provide a perspicuous representation of the sentences of natural languages, first-order predicate language seems inadequate to fill the bill. Not only have we such chestnuts as "Virtue is its own reward" that resist representation by first-order logic, but we also have all those sentences that motivate modal, epistemic, deontic and other higher order logics. If, on the other hand, we take the latter logics as perspicuous representations of sentences of natural languages, we seem to accept properties along with all sorts of other entities that are anathema to ontological ascetics. Thus, if first order logic will not do the trick of perspicuous representation by itself, there seems no reason to reject Aristotelian universals since we are driven to them in order to represent many natural language sentences anyway. There is also the problem that sets do not seem to provide a plausible way of analyzing properties; the latter remain resistantly intensional. The extension of sets cannot get the difference between those properties that hold of the same individuals (e.g., Quine's example of creature with a heart and creature with a liver), since the corresponding sets are coextensive, at least if all set members must be actual individuals. Opening the door to possible individuals as set members will do the trick for these cases as well as marking a difference between properties such as being a unicorn and being a centaur that are true of possible but no actual individuals. But if we open the door here, why not let the quantifiers of first-order predicate logic range over all possible individuals as well? After all, if we did, we could offer the usual modern analyses of categorical sentences and almost all of the problematic arguments in traditional logic would go through fine. This move, though tempting, won't palliate every semantic pain. The problem is 
property terms which are necessarily not true of any possible individual, e.g., "is a round square." Analyzing these properties into the empty set will only be satisfying if we see no difference between being a round square and a married bachelor. Ontologico-semantic simplicity, then, does not seem to give us good reason to prefer modern to traditional logic as long as we are after perspicuous representation; in fact, simplicity seems to push us towards traditional logic insofar as we apparently need properties in our ontico-semantics anyway.

The final reason that might lead us to prefer modern to traditional logic is ontological in something like Heidegger's sense of 'ontological', i.e., a conception of what it means to Be. Russell (1971, p. 168) of course reminded us that it is vital to have a robust sense of reality when we do logic; never mind that his sense of reality led him to logically proper names, bare particulars, and negative facts. By and large, twentieth-century Anglo-American philosophy's robust sense of reality has led it to understand existence as continuous, if sometimes small and brief, spatial and/or temporal location. This notion of existence is, I think, close to or the same as Heidegger's conception of the understanding of Being as presence from Descartes on. The conception leads to a fairly sharp distinction between what exists and what does not: properties, relations, fictions and mythologies all go on the scrap heap of ontology. On Heidegger's view (1969), in contrast, the existence sense of 'to be' encompasses different modes of Being. ${ }^{6}$ Thus, properties and individuals, fictions and mythological creatures, possible individuals and possible states of affairs might all exist, but if they exist, they do so in different ways. On Heidegger's view, the unity of the concept of Being is a unity of analogy or of relatedness rather than the formal unity of the usual modern concept of existence. It seems clear that the modern notion of existence is at least contingently wedded to modern logic by the usual extensional semantic accounts of that logic since concrete individuals must be located in both space and time. Thus, if we accept the modern notion of existence, then we should reject traditional logic. On the other hand, a Heideggerean notion of modes of Being would permit us to hold on to traditional logic since it makes it at least possible that the entities needed for the semantics of traditional logic have some sort of Being. But if, as I suspect, the question of which of these two ontological views is better is like the question of whether desert or tropical landscapes are preferable, I do not see that these considerations give us a reason to choose one logic over the other.

If there are no grounds that provide good reason for choosing one logic over the other, what are we to do? A response implicit in the treatment of traditional logic in most modern logic texts is to ignore the question raised above. Pressed for reasons, one might say that we have not yet got decisive reasons for choosing one or the other, but that we trust that such reasons will be forthcoming. This is not, to be sure, an intellectually satisfying response, but if reasons have to come to an end 
somewhere it might as well be here. But ignoring the question and expressing faith will not do if reasons of the sort considered in Section I are relevant to the question, since it appears there are reasons that might be adduced to respond to the question. However, the discussion above suggests that it will be difficult to find a decisive result on the matter by appeal to reasons.

A reformist response would be to deny that we must choose between the two logics insofar as we are looking for a perspicuous representation of natural language. This solution takes as its key the analyses offered by the two logics to categorical sentences such as "All unicorns are white." The reformist solution would claim that the difference between the two logics shows us that there is an unrecognized semantic ambiguity in such sentences, since they may be read either in the modern logic version as "Whatever individual is a unicorn is also white" or in the traditional logic version as "Unicornness is wholly included in whiteness." This solution is not without its discomforts. I, at least, am sympathetic to Kripke's claim $(1980$, p. $85 \mathrm{n})$ that semantic theory ought to avoid whenever possible solving its problems by "discovering" semantic ambiguities?. Once we open the door to philosophical "discovery" of ambiguity, it is hard to close it. For example, to return to "Virtue is its own reward," we could take this sentence to show an ambiguity in that we use a property term both as a value of a variable in "Virtue is its own reward" and as a predicate in "Anyone who has virtue is rewarded." There is no reason to think that the alleged ambiguity in property terms will appear only in this or in a very few cases. Thus, on this move, entirely unsuspected ambiguity threatens to proliferate.

Not only is there a worry about proliferating ambiguity with this move, but the ascription of ambiguity on the grounds of alleged logical form seems to be based on one of two problematic views about the relation between logic and language. The first, a version of which we can find in Frege, early Wittgenstein, Russell, Carnap, Quine, and others, is that the necessity of logic always trumps the apparent features of natural language. From Frege's work in the 1880s until at least the middle of the twentieth century, modern logic was generally seen as an uncontroversial site of necessity; once Quine showed that analyticity was problematic, modern logic became the only uncontroversial site of necessity. One aspect of much of the practice of analytic philosophy since Frege has been to use logic as a means of revealing the supposed underlying semantic structure of natural language. The problem has been to figure out how to mold natural language to the demands of logic so that we could see the logical structure of enough natural language. Russell's reading of "The present emperor of America is short" as a disguised conjunction became the model of semantic analysis. In contrast to the 'hardness' of logic, natural languages are correctly seen as (at least partly) conventional, historical, and fluid. However, we do indeed make deductive arguments, some good and some bad, in natural language; the good ones appear to require something other than squishy natural language to underwrite the necessity by which the conclusions follow from their premises. It is easy in these circum- 
stances to see modern logic as the universal core of natural languages or as the transcendental ground against which arguments in any natural language are to be evaluated. Thus, if there is a clash between the requirements of logic and the apparent structure of a natural language, logic will be seen as the guide to how it really is underneath surface appearances or to how natural language should be. However, this view of the relation of logic to natural languages has force only insofar as we hold that there is one and only one correct logic. If there are multiple logics and there is an argument marked as valid by one and invalid by another, necessity alone cannot determine whether the argument in question is valid or not. If the arguments of Section I are correct, we are not in a position to claim that either modern logic or traditional logic is the uniquely correct logic. The situation is exacerbated if we are willing to take the New Syllogistic or intuitionist logic or both as serious candidates for adequate logics. Thus, one version of the reformist move seems to wait on the establishment of one and only one logic as the correct one. $^{8}$

The reformist move might also be underwritten by a view like Davidson's, which takes a particular logic as an empirical theory of natural language. On this base, the discovery of alleged ambiguity would be seen as analogous to the discovery by an empirical science that things we had taken to be of a single type turn out to be two or more types. A standard example of the latter is the geologic discovery that what had been thought to be the single mineral jade is actually one of two distinct minerals, jadeite or nephrite. It is worth noting, however, that the geological distinction between jadeite and nephrite was made on the basis of both a single more or less unified theory and on the basis of the results of empirical tests that are built into that theory. The alleged reformist ambiguity, in contrast, relies on two different logics, two different "theories" of natural language. Moreover, the "data" for such a distinction in meaning is just the matter in dispute: which arguments are valid and which sentences are true. Thus, there are crucial disanalogies between the actual scientific case and the apparent philosophical case. Furthermore, at least for those who accept a sharp distinction between fact and value, there is the difficulty of showing how a descriptive account of the logical structure of natural languages can serve as a tool for making the normative distinction between valid and invalid arguments.

A radical response follows Wittgenstein's move from the Tractatus to the Investigations by taking seriously his comment $(1963, \# 81)$ that

in philosophy we often compare the use of words with games and calculi which have fixed rules, but cannot say that someone who is using language must be playing such a game. ... [because] ... logic does not treat of language $\ldots$ in the sense in which a natural science treats of a natural phenomenon, and the most that can be said is that we construct ideal languages.

On this view, logics are constructed as objects for both comparison with and contrast to natural language rather than as means of analysis. ${ }^{9}$ The argument patterns presented in a given logic are useful as perspicuous re-presentations of what 
we already do in natural language: a re-presentation is perspicuous to the extent that it replicates in a clearer and/or more systematic way what we already do with the natural language sentences re-presented. Although it might seem that this view would require giving up all logical necessity, we can reconceive the necessity of logic as parallel to that of geometrical systems. Both Euclidean and Riemannian geometries, as well as the strictly infinite number of other geometries, are necessary, but their necessity is internal. That is, given certain geometrical propositions or axioms, certain other propositions are also necessarily true and yet other propositions are necessarily false. However, no geometry can claim to be the correct geometry in the sense either of being unique or being the sole accurate description of physical, let alone lived in, space. The question of which is the correct geometry is an empirical and practical question. Moreover, as we know, we in fact use different geometries for different purposes: a Riemannian geometry works the best for cosmology and a Euclidean one for building bridges and houses. The normative force of geometry is hypothetical rather than categorical. That is, no geometry tells us that we must think about space in the propositions it contains. Rather, once we have settled the empirical and practical questions of the most appropriate geometry for thinking about a particular space, we ought to accept the propositions of that geometry as our guide for what we ought and ought not think about the space. Once a geometry is shown to be complete and consistent, it becomes a candidate for use in thinking about some space or other. Similarly, on the view of all logics as constructed, the normative force of logic becomes hypothetical rather than categorical. That is, our guiding logical norm would be "If you accept these arguments, you ought to accept these other arguments as valid and reject those as invalid" rather than being "Any rational being must accept these and only these arguments as valid and those and only those as invalid." Any logic that has been shown to be consistent and complete, in the sense of providing a means of proving all valid arguments expressible in the symbolism, is a candidate for symbolizing some set of arguments or other. Although this view deflates the logical necessity and the normative force attending formal logic, the move neither dispenses with formal logic nor relegates it to the position of an historical curiosity. However, it does dispense with the sort of automatic application of one formal logic that has characterized much of the practice of analytic philosophy since the invention of modern logic.

Viewing a variety of formal logics as useful tools for the re-presentation of arguments in natural language also calls into serious question the Quinean ontological business of determining ontological commitments of languages and theories by means of the values of variables. The practice proceeds by first assigning a logical form, i.e., a symbolization in some formal logic, to the sentences of the language or theory, and then determines the alleged ontological commitments of the language or theory by following Quine's dictum that to be is to be a value of a bound variable. As long as we seem to have one and only one correct logic, the first step proceeds with little difficulty other than sentences in the target language 
or theory that resist plausible symbolization. But the presumption that there is a uniquely correct logic encourages us to dismiss the recalcitrant sentences as senseless, logically confused, or logically ill-formed, even though those sentences are entirely at home in the use of the language or theory. If we accept a variety of logics, failing to find a symbolization in one of them is not the end of the story, since there might be a plausible symbolization in another. Furthermore, if there is among our logics one that resists extensional semantics, as I have suggested traditional logic does, then Quine's ontological standard appears to lose its force as the final word on ontological commitment. Giving up the ontological use of logic would have the benefit, to my mind at least, of leading philosophers to give up the embarrassing intellectual imperialism with which some philosophers treat the discourse of our colleagues in art and literary criticism, religion and anthropology. Most philosophers hold that there are no pictorial subjects, characters, gods, or witches. Those philosophers at times claim on that basis that their colleagues cannot say anything true when they speak in the particular form about such alleged pseudo-entities yet cannot help but make trivially true claims when they speak with sufficient generality about those same beings.

Perhaps the most difficult loss as a consequence of accepting the radical response would be giving up the ideal of a logic that will capture 'the' logic of natural languages. That ideal, whether the logical structure of language was seen as a matter of necessity or of empirical accuracy, has been deeply embedded in analytic philosophy since Frege. On both versions of the ideal, formal logic has a methodological priority over natural language; on the necessity version, the priority is also theoretical and perhaps ontological. But, as Ryle (1968, p. 30) reminded us, people were making valid arguments and rejecting invalid ones before Aristotle-or Frege, or Russell and Whitehead for that matter-codified some of the patterns of human inferential practice. The radical response takes Ryle's suggestion seriously by reversing the relative priority of natural language and logic in such a way that natural language is the ground from which logics get their value. Rather than logics being already there in or even before human practices of language, the radical response takes the practices of natural languages to be the ground from which logics grow and are nourished. As noted above, on the radical view, logics are useful in application as perspicuous re-presentations of some of the practices, especially the inferential practices, which are already a part of natural languages. In order to see whether a given symbolism is a useful re-presentation, we must have a clear view of that which is to be re-presented, that is, we must have a careful clear description of the natural language inferences accepted and those rejected and the sentences held true and those held false. Although some 'hardheaded' formal logicians view such 'merely' descriptive work with disdain, providing the required descriptions is of course one of the tasks that informal logicians have taken on. On the radical view, the 'soft' work of informal logicians, far from being of little logical interest, is the work necessary if formal logic is to have more value than eine Glasperlenspiel. 
As usually happens when 'mere' human practices are taken as the bedrock on which we stand, there will be worry that the practices cannot be criticized, and perhaps even skeptical worry that the practices are utterly wrong-headed. As noted above, the radical view accepts the hypothetical logical norm of the form that if you accept (or reject) argument A you should accept (or reject) argument $B$. Instantiations of this form certainly permit criticism of arguments made within a given practice. But what of the practices themselves? The key is to remember that most, if not all, of our practices aim towards purposes other than merely their own continuation. Insofar as the arguments accepted within a practice stand in the way of the practice furthering its internal ends, those arguments should be subject to logical criticism, i.e., should be counted as bad arguments and serve as a motive for revising the practice. But, the uneasy might reply, aren't incorrect inferences sometimes useful? Sometimes they are, but only in the way that playing a lottery is a useful way of making a living: sometimes we get lucky, but it would be foolish to count on luck. Cases of incorrect deductive inferences that turn out lucky are, in fact, among the things that make formal logics useful. Suppose we have an invalid argument that led someone to a useful belief. Formal logic, used in the way the radical view suggests, provides a perspicuous re-presentation of the argument and shows us in a system relative way why the argument is invalid. But that is to show us why we ought not rely on the pattern of argument, even if in this case things turned out well. To be sure, the radical view will not provide satisfaction for those who want something beyond the human realm to provide an imprimatur for human inferential practices. The radical view does indeed require that we give up appealing to those inferences that are warranted in every possible world - supposing we could determine in a non-circular way which inferences were so honored -in order to underwrite our own deductive inferences.

Perhaps it is time for a bit of skepticism about the tail wagging the dog while proclaiming its superiority to the dog..$^{10}$

\section{Notes}

'Robin Scott (1989, p. 183) claims that 53a3-14 shows that Aristotle "was aware of all the socalled 'subaltern' moods, together with the remaining fourth figure moods not already included." ${ }^{2}$ Some might be more comfortable calling the intuitions I note here and below linguistic than logical. I do prefer 'logical' to 'linguistic' because I am focusing on intuitions about inferences between sentences and the truth-value of sentences rather than those about meaningfulness or grammaticality. Some might also object to appealing to students' intuitions, but such intuitions are perhaps more reliable than our more educated intuitions, just because students have not (yet) been trained out of their initial logical intuitions.

3 One place where this point is worked out in detail is in unpublished notes taken by Nathan Ucuzoglu (Salmon) on Saul Kripke's class "Is Logic Empirical" given in the Spring Quarter, 1975, at UCLA. The notes suggest that Church has made a similar point, but I have not been able to track down where. Kripke's point is that if we try to build existential import into the A-form in order to save the syllogistic inferences, we lose either inferences within the square or some of the 
other immediate inferences. As noted above this is just what happens in New Syllogistic; see, for example, Sommers (1982, pp. 289-91)

${ }^{4}$ The semantic reasons here might be supplemented by the syntactic reasons offered by proponents of the New Syllogistic for preferring their "natural" logic to "constructivist" logic. While their syntactic reasons carry some weight for monadic predicates, the account of relational predicates seems labored, so I take syntactic considerations to be a wash. For the scare quotes on the alleged types of logics, see note 8 .

${ }^{5}$ I am here intentionally assuming an intensional rather than extensional reading of categorical sentences, e.g., A-form sentences (All A are B) are to be read as 'A is wholly included in B' rather than 'All things that are $A$ are also $B$ '. There is no marking of these different readings in Aristotle's original language. For example, the McKeon translation speaks of terms as "containing", "belonging to" and being "related to" one another as well as using such expressions as "everything", "nothing" and "something" that suggest an extensionalist reading. I would suggest that the distinction arrives on the philosophical scene later, so it would be anachronistic to impose one or the other without reason. One reason for preferring the intensional reading is of course that it allows the problematic inferences to go through.

${ }^{6}$ I do not mean to suggest that Heidegger, who delineates three modes of Being, would have countenanced all the modes of Being of the beings I list in the next sentence. Heidegger (1969, p. 22) attributes to Aristotle the claim that the unity of the concept of Being must be a unity of analogy since there are different sorts of Being; he also claims that all philosophy since Aristotle neglected that insight. My own intuition agrees with Heidegger that 'Being' is not univocal, but takes 'Being" to be a family resemblance concept rather than an analogical or relational one.

${ }^{7}$ The notes from Kripke's class referred to in note 3 give rise to a certain irony when juxtaposed with his comment on ambiguity. According to the notes, Kripke saw the dilemma posed by the formal inconsistency or irreducibility of the two logics as seeming to drive us to say that we do not know what we mean by universal-universal sentences in the natural language. The notes indicate that Kripke was uncomfortable with this move, but apparently was without a more satisfying solution at the time.

* The view that there is one and only one logic is so deeply embedded that even my computer resists making 'logic' plural. But then it also resists a plural for 'geometry.'

"On this view, Sommers' (1982, pp. 2-4) distinction between a "constructivist" logic like Frege's and a "natural" logic like his own is a distinction without a difference, since all logics are constructed and all have their point in their complex relations with natural language.

${ }^{10}$ An earlier version of this paper was read to the Ontario Society for the Study of Argumentation at Brock University, 1999.

\section{References}

Aristotle. (1941). The Basic Works of Aristotle, (R. McKeon, ed. and trans.). New York: Random House.

Austin, J. L. (1970). "Ifs and Cans. " In J. O. Urmson and G. J. Warnock (eds.), Philosophical Papers ( $2^{\text {nd }}$ edition). New York: Oxford University Press.

Davidson, D. (1965). "Theories of Meaning and Learnable Languages." In Y. Bar-Hillel (Ed.), Proceedings of the 1964 International Congress for Logic, Methodology and Philosophy of Science (pp. 383-394). Amsterdam: North-Holland Publishing Co.

Davidson, D. (1967). "Truth and Meaning." Synthese, 17, 304-323.

Davidson, D. (1969). "On Saying That." Synthese, 19, 130-146. 
Davidson, D. (1970), "Action and Reaction." Inquiry, 13, 140-148.

Englebretsen, G. (1981). Three Logicians. Atlantic: Highlands Humanities Press.

Englebretsen, G., (ed.). (1987). The New Syllogistic. New York: Lang.

Heidegger, M. (1962). Being and Time. (Macquarrie and Robinson, trans.) New York:

Harper and Row.

Kripke, S. (1980). Naming and Necessity. Cambridge: Harvard University Press.

Russell, B. (1971). "Descriptions." In J. F. Rosenberg and C. Travis, Readings in the Philosophy of Language, pp. 166-175. Englewood Cliffs, N.J.: Prentice-Hall.

Ryle, G. (1968). The Concept of Mind. New York: Barnes and Noble.

Scott, R. (1989). Aristotle: Posterior Analytics. Indianapolis: Hackett.

Sommers, F. (1982). The Logic of Natural Language. New York: Oxford University Press.

Ucuzoglu (Salmon), N. (1975). Unpublished notes on Saul Kripke's class "Is Logic

Empirical." Spring Quarter: UCLA.

Wittgenstein, W. (I963). Philosophical Investigations. Oxford: Blackwell.

Jesse P. Bohl Department of Philosophy College of William and Mary PO Box 8795 Williamsburg, VA 23187 USA jpbohl@wm.edu 